\title{
Commentary
}

\section{Ridding Canadian medicine of conversion therapy}

\author{
Travis Salway PhD, Florence Ashley BCL/JD LLM (Bioeth)
}

Cite as: CMAJ 2022 January 10;194:E17-8. doi: 10.1503/cmaj.211709

${ }^{66} \mathrm{C}$

onversion therapy" is an umbrella term describing a poorly defined set of psychological, behavioural, physical and faith-based interventions that work to suppress same-sex attraction, or to deter patients from expressing gender identities discordant with sex assigned at birth. ${ }^{1,2}$ More than 50 health professional organizations - including the Canadian Psychiatric Association and American Medical Association - have issued consensus statements denouncing conversion therapy, owing to substantial empirical evidence that these practices are ineffective and associated with poor health outcomes, notably including suicide ideation and attempts. ${ }^{3-7}$ Despite these denouncements, conversion therapy continues to occur in Canada, in both licensed and unlicensed practice settings, affecting as many as 10\% of Two-Spirit, lesbian, gay, bisexual, transgender and queer (2SLGBTQ+) people. ${ }^{8}$ The recent passage by the federal Parliament of Bill C-4, banning conversion therapy, creates a new opportunity for synergy between medicine and the law, protecting the rights and health of 2SLGBTQ+ people in Canada.

The central feature of conversion therapy and analogous practices (e.g., intersex surgeries, denial of gender-affirming medical care) is an ideology that favours heterosexual and cisgender identities and behaviours over all others. This ideology, which includes cissexism and heterosexism, maintains the socionormative assumption that cisgender and heterosexual identities are more legitimate than those of $2 \mathrm{SLGBTQ}+$ people. $^{1}$

Recent empirical research from Canada clarifies that conversion therapy is not a monolithic practice. In Canada, as in the United States, it is not exclusively the domain of unregulated practitioners. ${ }^{2,4}$ In a 2019/20 survey of 9214 gay, bisexual, queer and Two-Spirit men, $10 \%$ said they had been exposed to conversion therapy during their lifetime, $30 \%$ of whom had experienced the practice in a licensed health care provider's office. ${ }^{8}$ In interviews, conversion therapy "patients" described having attended interventions in a remarkably wide range of settings: churches, camps, conferences, online chats, prayer groups, regulated and unregulated counsellors' offices, and medical offices. ${ }^{1}$ Although contemporary data on conversion therapy are limited by the constrained sampling methods required to reach 2SLGBTQ+ people and survivors of conversion therapy, these data allow a glimpse of the scope and nature of the problem at

\section{Key points}

- Conversion therapy continues to occur in both regulated and unrelated settings in Canada, prompting federal, provincial and territorial, and municipal governments to have debated and enacted dozens of legislative bans over the past 6 years.

- Health care providers, patients, parents, policy-makers and politicians need improved clarity on the nature of conversion therapy, to identify and avoid analogous practices that may harm Two-Spirit, lesbian, gay, bisexual, transgender and queer (2SLGBTQ+) patients.

- The defining feature of conversion therapy and analogous practices (e.g., intersex surgeries, denial of gender-affirming medical care) is an ideology that favours heterosexual and cisgender identities and behaviours over all others.

- Canada's medical regulators should act to augment any federal legislation, by making it clear that they will take prompt disciplinary action against members who cause harm through engaging in or supporting conversion therapy interventions.

- With the passage of Bill C-4 and stronger professional governance, Canada's physicians will be doubly incentivized to reject cissexism and heterosexism, and to embrace a more inclusive approach to health care.

hand. There are no contemporary data on the attitudes of licensed Canadian health care providers toward conversion therapy; however, a recent publication from the United Kingdom shows that more than $4 \%$ of psychotherapists have treated at least 1 patient in order to reduce same-sex attraction. ${ }^{9}$ Licensed health care providers' histories of "treating" transgender patients in order to align gender identity with sex assigned at birth are likely much more prevalent. ${ }^{4,8}$ Data from the national 2019 Trans PULSE Canada survey of 2033 individuals indicate that, among transgender and nonbinary respondents who have undergone conversion therapy, $27 \%$ reported that this practice involved a physician or nurse or both (Ayden Scheim, Drexel University, Philadelphia, PA; personal communication, 2021). Evidence about the forms these practices take is heterogeneous; although some Canadian interviewees have disclosed physically severe practices like electroconvulsive therapy, most describe talk therapies, all with an explicit or implicit bias against an outcome that included a 2SLGBTQ+ identity. 1,7 
Canada's medical regulators should act to augment any federal legislation by making it clear that they will take prompt disciplinary action against members who cause harm through engaging in or supporting conversion therapy interventions. Although several provinces and territories (e.g., Ontario, Nova Scotia and Yukon) have passed legislation prohibiting the use of public funds for conversion therapy, it is unclear how these laws are currently enforced, and mutually reinforcing strategies to deter conversion therapy practices - including legislation and regulatory action - are likely required, given the insidious and covert forms these practices often take. ${ }^{1}$ Canadian citizens have the right to access 2SLGBTQ+-affirming medical care. Therefore, individual physicians who are unfamiliar or uncomfortable with providing gender-affirming medicine have a responsibility to refer their patients to doctors who can provide these services. ${ }^{10}$

By identifying the defining feature of conversion therapy as an underlying ideology that favours heterosexual and cisgender identities and behaviours over all others, health care providers, users and policy-makers can enact more precise and effective policies to achieve sexual and gender health equity in Canada. With the passage of Bill C-4 and stronger professional governance, Canada's physicians will be doubly incentivized to reject cissexism and heterosexism, and to embrace a more inclusive approach to health care. The ingredients are in place to rid our medical system of conversion therapy once and for all.

\section{References}

1. Kinitz DJ, Goodyear T, Dromer E, et al. "Conversion therapy" experiences in their social contexts: a qualitative study of sexual orientation and gender identity and expression change efforts in Canada: Les expériences de "thérapie de conversion" dans leur contexte social: une étude qualitative. Can J Psychiatry 2021 July 9 [Epub ahead of print];7067437211030498. doi: 10.1177/07067437211030498.

2. Streed CG, Anderson JS, Babits C, et al. Changing medical practice, not patients - putting an end to conversion therapy. N Engl J Med 2019;381: 500-2.

3. Salway T, Ferlatte O, Gesink D, et al. Prevalence of exposure to sexual orientation change efforts and associated sociodemographic characteristics and psychosocial health outcomes among Canadian sexual minority men. Can J Psychiatry 2020;65:502-9.

4. Turban JL, Beckwith N, Reisner SL, et al. Association between recalled exposure to gender identity conversion efforts and psychological distress and suicide attempts among transgender adults. JAMA Psychiatry 2020;77: 68-76.

5. Ashley F. Model law - prohibiting conversion practices. SSRN 2019 May 28. Available: https://papers.ssrn.com/sol3/papers.cfm?abstract_id=3398402 (accessed 2021 Oct. 2).
6. Blosnich JR, Henderson ER, Coulter RWS, et al. Sexual orientation change efforts, adverse childhood experiences, and suicide ideation and attempt among sexual minority adults, United States, 2016-2018. Am J Public Health 2020; May 21;110(7) [Epub ahead of print]:e1-e7. doi: 10.2105/AJPH.2020.305637.

7. Goodyear T, Kinitz DJ, Dromer E, et al. "They want you to kill your inner queer but somehow leave the human alive": delineating the impacts of sexual orientation and gender identity and expression change efforts. J Sex Res 2021 Apr. 19 [Epub ahead of print];1-11. doi: 10.1080/00224499.2021.1910616.

8. Salway T, Juwono S, Klassen B, et al. Experiences with sexual orientation and gender identity conversion therapy practices among sexual minority men in Canada, 2019-2020. PLoS One 2021;16:e0252539.

9. King M. Attitudes of therapists and other health professionals towards their LGB patients. Int Rev Psychiatry 2015;27:396-404.

10. Lam JSH, Abramovich A. Transgender-inclusive care. CMAJ 2019;191:E79.

Competing interests: Travis Salway reports receiving grants from the Canadian Institutes of Health Research, Social Sciences and Humanities Research Council, Simon Fraser University CommunityEngaged Research Initiative, BC SUPPORT Unit, and the Michael Smith Foundation for Health Research. Dr. Salway is supported by a Michael Smith Foundation for Health Research Scholar Award. Florence Ashley is supported by a SSHRC Joseph-Armand Bombardier Doctoral Scholarship. Both authors work in close collaboration with Two-Spirit, lesbian, gay, bisexual, transgender and queer community-based organizations to identify policies and interventions that support health equity for these communities. No other competing interests were declared.

This article has been peer reviewed.

Affiliations: Faculty of Health Sciences (Salway), Simon Fraser University, Burnaby, BC; British Columbia Centre for Disease Control (Salway); Centre for Gender and Sexual Health Equity (Salway), Vancouver, BC; University of Toronto Faculty of Law and Joint Centre for Bioethics (Ashley), Toronto, Ont.

Contributors: Travis Salway drafted the manuscript. Both authors contributed to the conception and design of the work, revised it critically for important intellectual content, gave final approval of the version to be published and agreed to be accountable for all aspects of the work.

Acknowledgements: The authors thank the courageous conversion therapy survivors who have tirelessly told and retold their stories so that the rest of us would finally take action to combat these traumatic practices.

Content licence: This is an Open Access article distributed in accordance with the terms of the Creative Commons Attribution (CC BY-NCND 4.0) licence, which permits use, distribution and reproduction in any medium, provided that the original publication is properly cited, the use is noncommercial (i.e., research or educational use), and no modifications or adaptations are made. See: https://creativecommons.org/ licenses/by-nc-nd/4.0/

Correspondence to: Travis Salway, travis_salway@sfu.ca 